\title{
Cell apoptosis induced by a synthetic carbazole compound LCY-2-CHO is mediated through activation of caspase and mitochondrial pathways
}

\author{
Ming-Jen Hsu ${ }^{a}$, Yee Chao ${ }^{b}$, Ying-Hsin Chang ${ }^{a}$, Feng-Ming Ho ${ }^{c}$, Li-Jiau Huang ${ }^{d}$, \\ Ya-Ling Huang ${ }^{\mathrm{d}}$, Tien-Yau Luh ${ }^{\mathrm{e}}$, Chih-Ping Chen ${ }^{\mathrm{c}}$, Wan-Wan Lin ${ }^{\mathrm{a}, *}$ \\ ${ }^{a}$ Department of Pharmacology, College of Medicine, National Taiwan University, Taipei, Taiwan \\ ${ }^{\mathrm{b}}$ Cancer Center, Veterans General Hospital, Taipei, Taiwan \\ ${ }^{c}$ Department of Internal Medicine, Tao-Yuan General Hospital Department of Health the Executive Yuan, Tao-Yuan, Taiwan \\ ${ }^{\mathrm{d}}$ Graduate Institute of Pharmaceutical Chemistry, China Medical College, Taichung, Taiwan \\ ${ }^{\mathrm{e}}$ Department of Chemistry, National Taiwan University, Taipei, Taiwan
}

Received 27 October 2004; accepted 14 April 2005

\begin{abstract}
The mechanisms involved in the apoptotic effect of LCY-2-CHO [9-(2-chlorobenzyl)-9H-carbazole-3-carbaldehyde], a synthetic carbazole derivative identified as an anti-inflammatory compound, were studied. Cell cycle analysis by propidium iodide staining in human THP-1 monocytic leukemia cells showed the ability of LCY-2-CHO to increase cell population in sub-G1 stage with time- and concentration-dependent manners. LCY-2-CHO-mediated cell death was also demonstrated by DNA laddering and was not related to the release of lactate dehydrogenase. Apoptosis in THP-1 cells induced by LCY-2-CHO was accompanied by the Bid cleavage, collapse of mitochondrial transmembrane potential, the release of cytochrome $c$ and the activation of caspase-3. The apoptotic effect of LCY-2-CHO was diminished by the presence of zVEID-fmk (caspase-6 inhibitor), zIETD-fmk (caspase-8 inhibitor), and zVAD-fmk (non-selective caspase inhibitor), but was not altered by several antioxidants, and cathepsin inhibitor. The Bid cleavage and loss of mitochondrial transmembrane potential, but not the cytochrome $c$ release, were reversed by zIETD-fmk. Comparing the cell selectivity of LCY-2-CHO, we found T-cell acute lymphoblastic CEM leukemia cells were sensitive to $1 \mu \mathrm{M}$ LCY-2-CHO, acute myeloid leukemia HL-60 cells underwent apoptosis at $10 \mu \mathrm{M}$, while adherent cancer cells, such as PC3, HT29 and MCF-7, were resistant to $30 \mu \mathrm{M} \mathrm{LCY-2-CHO} \mathrm{within}$ 24-h incubation. Taken together in the present study, we demonstrated LCY-2-CHO might be apoptotic for malignant hematopoietic cells but not anchorage-dependent cells. This action is mediated by an intrinsic caspase-dependent apoptotic event involving mitochondria. (C) 2005 Elsevier Inc. All rights reserved.
\end{abstract}

Keywords: LCY-2-CHO; Carbazole; Apoptosis; Caspases; Mitochondria

\section{Introduction}

Apoptosis is an essential process of the development and tissue homeostasis of most multicellular organisms, and the deregulation of apoptosis has been implicated in the pathogenesis of many disease states, such as cancers. In contrast to cells undergoing necrosis, apoptosis can prevent

Abbreviations: GSH, glutathione; LDH, lactate dehydrogenase; NAC, $N$-acetyl cysteine; ROS, reactive oxygen species; zVEID-fmk, Z-Val-GluIle-Asp-fluoromethylketone; zIETD-fmk, Z-Ile-Glu-Thr-Asp-fluoromethylketone; zVAD-fmk, Z-Val-Ala-Asp-fluoromethylketone; zYVADfmk, Z-Tyr-Val-Ala-Asp-fluoromethylketone; zVDVAD-fmk, Z-Val-AspVal-Ala-Asp-fluoromethylketone

* Corresponding author. Tel.: +886 2 23123456x8315; fax: +886223915297

E-mail address: wwl@ha.mc.ntu.edu.tw (W.-W. Lin). the occurrence of inflammatory response. This outcome is associated with the clearance of apoptotic cells by professional phagocytes and a subsequent non-inflammatory mechanism [1]. Besides aids the resolution of the inflammatory response, apoptosis in inflammatory cells, for example, fails to release their proinflammatory and cytotoxic contents [2]. Thus, apoptosis is generally regarded to be non-inflammatory and is crucial for the successful resolution of inflammation [3]. In contrast, persistence of inflammatory cells, which fail to respond to apoptotic signals, leads to damage of the surrounding tissue and exacerbation of inflammation. Moreover, in recent years the regulation of cell cycle and apoptosis has received much attention as a possible means of eliminating excessively proliferating cancer cells. Cancer occurrence requires the failure of the apoptotic safeguard mechanisms 
as well as the deregulation of the cell cycle [4]. Virtually many anticancer approaches including chemotherapy, hormones and radiation, induce cytotoxicity of tumor cells by apoptosis [5,6].

Initiation of apoptosis is controlled by regulation of the balance between life and death signals received by the cells [7]. It is therefore that specific therapies designed to change the balance between life and death signals in inflammatory leukemia cells, could therefore be of therapeutic benefit [8]. The transmission of death signals from the plasma membrane to the nucleus involves a number of different pathways. According to the involvement of degradation enzymes and mitochondria, extensive studies have identified several apoptotic pathways and mediators, which might be caspase-dependent, mitochondria-dependent, and/or caspase-independent protease cascades. Caspases receive signals induced by various cytotoxic factors and are frequently activated as the result of changes of mitochondrial membrane permeabilization, which causes the release of cytochrome $c$ from the mitochondrial inter-membrane space. Once in the cytosol, cytochrome $c$ triggers the assembly of a caspase activation complex, the apoptosome $[9,10]$. Apoptosome-activated caspase-3 can then trigger hallmarks of apoptosis by proteolytical cleavage and activation of a DNase, which mediates DNA fragmentation [11-13]. Caspases are not the unique mediators of programmed cell death. Serine proteases are implicated in cell death occurring without activation of caspase family members, or sequentially related to caspases [14-16].

LCY-2-CHO [9-(2-chlorobenzyl)-9H-carbazole-3-carbaldehyde], a carbazole compound (Fig. 1), was synthesized by the laboratory of Dr. L.J. Huang when she first investigated a series of related derivatives in anti-platelet aggregation [17]. Later several anti-inflammatory properties of LCY-2-CHO were shown, which include attenuation of neutrophil degranulation and superoxide anion $\left(\mathrm{O}_{2}{ }^{-}\right)$ generation [18], inhibition of lipopolysaccharide-induced $\mathrm{NO}, \mathrm{PGE}_{2}$ and TNF- $\alpha$ production in macrophages through the interference with p38 MAPK signaling pathway $[19,20]$. Following these findings, it was of great interest to investigate the effects of LCY-2-CHO in regulating cell viability, particularly for tumor cells. For this purpose, in

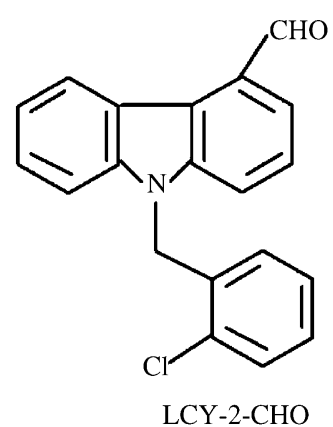

9-(2-chlorobenzyl)-9H-carbazole-3-carbaldehyde

Fig. 1. Structure of LCY-2-CHO. this study we examined the effects of LCY-2-CHO in hematopoietic leukemia cells and other adherent cancer cell lines. We observed the preference of LCY-2-CHO to induce apoptosis of hematopoietic leukemia cells, and the possible mechanisms involved in the apoptotic effect of LCY-2-CHO were investigated.

\section{Materials and methods}

\subsection{Materials}

LCY-2-CHO (purity > 99\%) was synthesized and dissolved in DMSO [18]. RPMI 1640, DMEM, fetal bovine serum, penicillin, and streptomycin were obtained from Gibco-BRL (Grand Island, NY). Horseradish peroxidaseconjugated anti-mouse antibodies and the enhanced chemiluminescence detection agent were purchased from Amersham Pharmacia Biotech (Piscataway, NJ). Rabbit polyclonal antibodies specific for procaspase-3, cytochrome $c$ and Bid were from Santa Cruz Biotechnology (Santa Cruz, CA). All reagents for sodium dodecyl sulfatepolyacrylamide gel electrophoresis were purchased from Bio-Rad Laboratories (Richmond, CA). zVEID-fmk (ZVal-Glu-Ile-Asp-fluoromethylketone), zIETD-fmk (Z-IleGlu-Thr-Asp-fluoromethylketone), zVAD-fmk (Z-ValAla-Asp-fluoromethylketone), zYVAD-fmk (Z-Tyr-ValAla-Asp-fluoromethylketone), zVDVAD-fmk (Z-ValAsp-Val-Ala-Asp-fluoromethylketone), and CA074Me were purchased from Calbiochem (San Diego, CA). Carboxyfullerene C60 was synthesized and provided by Dr. Tien-Yau Luh (Department of Chemistry, National Taiwan University, Taiwan) [21]. All other chemicals were obtained from Sigma Chemical Co. (St. Louis, MO). CytoTox96 non-radioactive cytotoxicity assay kit was purchased from Promega (Madison, WI).

\subsection{Cell culture}

Human THP-1 monocytic leukemia cells, T-cell acute lymphoblastic CEM leukemia cells and acute myeloid leukemia HL-60 cells obtained from American Type Culture Collection were maintained (cell density between $10^{5}$ and $10^{6}$ cells $/ \mathrm{ml}$ ) in RPMI 1640 medium supplemented with $10 \%$ heat-inactivated fetal calf serum, $100 \mathrm{U} / \mathrm{ml}$ penicillin and $100 \mu \mathrm{g} / \mathrm{ml}$ streptomycin at $37{ }^{\circ} \mathrm{C}$ with $5 \%$ $\mathrm{CO}_{2}$. Prostate PC 3 cancer cells, breast MCF-7 cancer cells, and adenocarcinoma HT29 cells were maintained in DMEM with similar supplements as described above.

\subsection{Propidium iodide staining for DNA content}

The propidium iodide staining by flow cytometry was used to measure the extent of cell death. Cells were initially seeded at $5 \times 10^{6}$ cells in 6-well plate and incubated in the indicated concentration of LCY-2-CHO or $0.1 \%$ DMSO 
for selected time periods. Following treatment, all cells were collected, and then centrifuged, washed once in phosphate-buffered saline (PBS) and resuspended in icecold $70 \%(\mathrm{v} / \mathrm{v})$ ethanol with vortexing and stored at $0{ }^{\circ} \mathrm{C}$ until analysis. Fixed cells were collected by centrifugation, washed once in PBS, and incubated in $400 \mu$ l phosphatecitric acid buffer $\left(0.2 \mathrm{M} \mathrm{Na}_{2} \mathrm{HPO}_{4}, 0.1 \mathrm{M}\right.$ citric acid, $\mathrm{pH}$ 7.8) for $10 \mathrm{~min}$ at room temperature and stained with $0.5 \mathrm{ml}$ propidium iodide staining buffer (1\% Triton $\mathrm{X}$ $100,1 \mathrm{mg} / \mathrm{ml}$ RNase A, $80 \mu \mathrm{g} / \mathrm{ml}$ propidium iodide) for more than $30 \mathrm{~min}$ in the dark. Before cytometric analysis, cells were filtered on a nylon mesh filter. The samples were analyzed using FACScan and Cellquest program (Becton Dickinson). Cell cycle distribution was also analyzed by flow cytometry $[22,23]$.

\subsection{Immunoblotting}

Following incubation in the presence of various stimuli for different time periods, cells were washed twice in icecold PBS then incubated with lysis buffer comprising $20 \mathrm{mM}$ Tris- $\mathrm{HCl}$ (pH 7.5), $0.5 \mathrm{mM}$ EGTA, 2 mM EDTA, $2 \mathrm{mM}$ dithiothreitol, $0.5 \mathrm{mM}$ phenylmethylsulfonyl fluoride, $1 \mathrm{mM}$ sodium orthovanadate, $10 \mu \mathrm{g} / \mathrm{ml}$ aprotinin and $10 \mu \mathrm{g} / \mathrm{ml}$ leupeptin. Equal protein concentrations $(\sim 60 \mu \mathrm{g})$ of cell lysates determined by the Bradford protein assay (Bio-Rad) were boiled in SDS sample loading buffer, and then fractionated on 10\% SDS-PAGE before blotting onto a nitrocellulose membrane. Blots were then incubated in $150 \mathrm{mM} \mathrm{NaCl}, 20 \mathrm{mM}$ Tris, and $0.02 \%$ Tween ( $\mathrm{pH}$ 7.4) containing 5\% non-fat milk, then were probed with peroxidase-conjugated anti-mouse IgG or anti-rabbit IgG. After washing with PBS, blots were developed by using an enhanced chemiluminescence kit according to the vendor's instruction before exposure to photographic film. In most experiments, the protein amount of $\alpha$-tubulin was regarded as an internal control.

\subsection{Lactate dehydrogenase (LDH) release assay}

The integrity of the plasma membrane of THP-1 cells was determined by monitoring the leakage of LDH. The CytoTox96 non-radioactive cytotoxicity assay kit was used to quantitatively measure LDH. Cells were treated with LCY2-CHO at indicated concentrations or $0.1 \%$ DMSO for $24 \mathrm{~h}$, and $\mathrm{LDH}$ released into the surrounding medium was then determined according to the manufacturer's instructions. Briefly, equal volume of $2 \times$ substrate solution [ $(1 \mathrm{mM}$ pyruvate, $0.2 \mathrm{mM} \mathrm{NADH}$ in $0.1 \mathrm{M}$ Tris- $\mathrm{HCl}$ ( $\mathrm{pH} 7.4$ )] was added to the medium, and the mixtures were incubated at $37{ }^{\circ} \mathrm{C}$ for $10 \mathrm{~min}$. Samples were read at the absorbance at $340 \mathrm{~nm}$ in a microtiter plate reader. The absorbance of RPMI culture medium without cells was considered as a blank. Lysis buffer added for $10 \mathrm{~min}$ was used as a positive control for complete cell necrosis. Data were then calculated as the percentage of lysis buffer-treated group.

\subsection{DNA laddering}

Cleavage of DNA into oligonucleosomal fragments, recognizable as a DNA ladder when electrophoresed on an agarose gel, is usually considered the biochemical hallmark of apoptosis. Genomic DNA was isolated using the Puregene kit \#D-5000 (Gentra Systems, Minneapolis, $\mathrm{MN})$. Briefly, following treatment with the test compound, cells were washed with PBS and lysed in cell lysis buffer containing Tris, EDTA, and SDS. After the addition of RNase A $(0.6 \mathrm{U} / \mathrm{ml})$, the mixture was incubated at $37{ }^{\circ} \mathrm{C}$ for $30 \mathrm{~min}$. Protein precipitation solution (ammonium acetate) was added to the samples to eliminate the contamination of proteins and was centrifuged at $2000 \times g$ for $10 \mathrm{~min}$. Cell lysates were treated with $100 \%$ isopropanol to precipitate DNA. The DNA pellet was washed with $70 \%$ $(\mathrm{v} / \mathrm{v})$ ethanol and dissolved in DNA hydration buffer containing Tris and EDTA. The DNA concentration was determined at $260 \mathrm{~nm}$ by spectrophotometry. DNA $(20 \mu \mathrm{g})$ was electrophoresed on a $1 \%(\mathrm{w} / \mathrm{v})$ agarose gel containing $0.5 \mu \mathrm{g} / \mathrm{ml}$ ethidium bromide. DNA fragmentation bands were photographed under UV light.

\subsection{Determination of mitochondrial transmembrane potential}

To evaluate mitochondrial transmembrane potential, cells without fixation were incubated with $30 \mathrm{nM}$ chloromethyl Xarosamine (CMXRos) (Molecular Probe, Eugene, OR) for $15 \mathrm{~min}$ at $37^{\circ} \mathrm{C}$. The cells were then analyzed using FACScan flow cytometer, as previously described [24].

\subsection{Cytosolic fraction isolation}

The procedure for isolation of the cytosolic fraction was described previously [25]. Briefly, cells $\left(1 \times 10^{8}\right)$ were washed in ice-cold PBS and spun at $400 \times g$ for 5 min at $4{ }^{\circ} \mathrm{C}$. The cell pellet was resuspended in $1 \mathrm{ml}$ of ice-cold buffer A [250 mM sucrose, $20 \mathrm{mM}$ HEPES-KOH ( $\mathrm{pH} 7.5$ ), $10 \mathrm{mM} \mathrm{KCl}, 1.5 \mathrm{mM} \mathrm{MgCl} \mathrm{m}_{2}, 1 \mathrm{mM}$ sodium EDTA, $1 \mathrm{mM}$ EGTA, $1 \mathrm{mM}$ DTT, $0.1 \mathrm{mM}$ phenylmethylsulfonyl fluoride, $10 \mu \mathrm{g} / \mathrm{ml}$ leupeptin and $10 \mu \mathrm{g} / \mathrm{ml}$ aprotinin]. Cells were lysed by 40 strokes with a Dounce glass homogenizer on ice. The lysate was centrifuged at $700 \times g$ for $10 \mathrm{~min}$ at $4{ }^{\circ} \mathrm{C}$ to remove nuclei and unbroken cells. The supernatant was removed and centrifuged at $14,000 \times g$ for $15 \mathrm{~min}$ at $4{ }^{\circ} \mathrm{C}$ to eliminate mitochondria. The resulting supernatant, the cytosolic fraction, was assayed for the protein concentration by the Bradford protein assay (Bio-Rad), and then boiled in SDS sample loading buffer. The supernatant was also assayed for glutamate dehydrogenase (GDH) activity [26]. Less than 5\% of the total cellular GDH activity (mitochondrial marker) was detected in supernatant after sample homogenization. The yield of GDH in both fractions was not affected by LCY-2-CHO and zIETD-fmk. 


\subsection{Caspase-3 activity assay}

The caspase-3 colorimetric assay kit was purchased from BioVision Research Products Co., Ltd., and the assay was performed exactly according to the manufacturer's protocol. Briefly, THP-1 cells $\left(5 \times 10^{6}\right)$ were resuspended in $50 \mu \mathrm{l}$ of chilled cell lysis buffer and incubated on ice for $10 \mathrm{~min}$. Cell debris was separated from the supernatant by centrifuging at $14,000 \times g$ for $5 \mathrm{~min}$. Equal volume of $2 \times$ reaction buffer and $5 \mu \mathrm{l}$ of $4 \mathrm{mM}$ DEVD-pNA (Asp-GluVal-Asp-p-nitroanilide) substrate $(200 \mu \mathrm{M}$ final concentration) were added to the supernatant, and the mixtures were incubated at $37^{\circ} \mathrm{C}$ for another $2 \mathrm{~h}$. Samples were read at the absorbance at $405 \mathrm{~nm}$ in a microtiter plate reader.

\subsection{Flow cytometry for ROS formation}

$2^{\prime}, 7^{\prime}$-Dichlorodihydrofluorescin diacetate (DCFH-DA) was used as an indicator for the formation of intracellular reactive oxygen species (ROS). Cells were pretreated with DCFH-DA (50 $\mu \mathrm{M})$ for $30 \mathrm{~min}$, and then LCY-2-CHO was added for different time periods. Once ROS was generated, the DCFH oxidation product, DCF fluorescence can be detected by flow cytometer (FACScan, Becton Dickinson). The fluorescence was assessed by counts of FL1-H, and the mean value would represent the ability of a chemical compound to induce ROS formation.

\subsection{Statistic evaluation}

Values are expressed as the mean \pm S.E.M. of at least three experiments. Student's $t$ tests were used to assess the statistical significance of the differences, with " $p$ " values of less than 0.05 being considered statistically significant.

\section{Results}

\subsection{Induction of apoptosis in THP-1 cells by LCY-2-CHO}

Treatment of THP-1 cells with LCY-2-CHO led to cell apoptosis, as determined by cell-cycle analysis using flow cytometry, which is dependent on the content of DNA in cells. The extent of apoptosis defined as the percentage of cells in the sub-G1 fraction of the cell cycle was increased (Fig. 2). When examining the concentration-dependent effect of LCY-2-CHO, the results indicated that concentrations higher than $1 \mu \mathrm{M}$ are required for apoptotic ability seen after 48-h incubation. LCY-2-CHO-elicited THP-1 cell apoptosis was also in a time-dependent manner (Fig. 2A). Loss of cell viability was detected in about $60 \%$ of cells in the presence of $10 \mu \mathrm{M}$ LCY-2-CHO for $24 \mathrm{~h}$. Upon prolonged stimulation with $10 \mu \mathrm{M}$ LCY-2$\mathrm{CHO}$ up to $48 \mathrm{~h}$, the population of dead cells was approximately $80 \%$. Accompanied with sub-G1 increase, a sig-
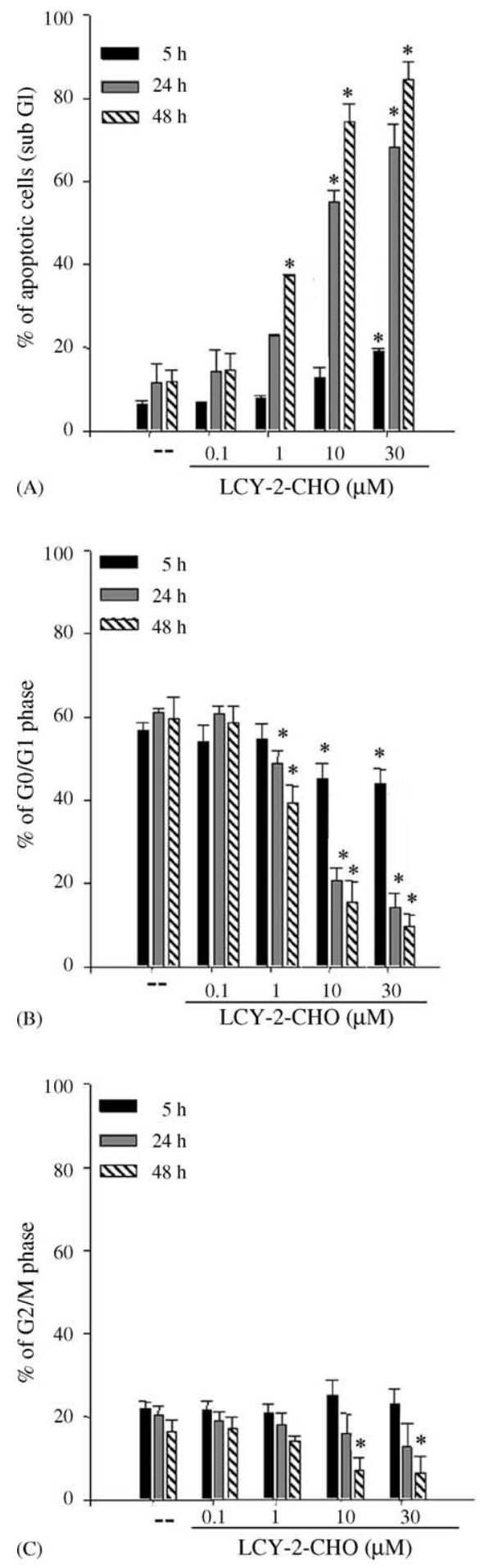

Fig. 2. Flow cytometric analysis quantification of cell-cycle distribution in THP-1 monocytic leukemia cells. THP-1 cells were incubated with vehicle, indicated concentrations of LCY-2-CHO for different time periods. Following incubation, cells were stained by propidium iodide and cell cycle distribution, including sub-G1 (A), G0/G1 (B) and G2/M phases (C), was determined by flow cytometry. Each column represents the mean \pm S.E.M. of at least three independent experiments. ${ }^{*} P<0.05$ as compared with the control group without LCY-2-CHO treatment.

nificant decrease of cell cycle at G0/G1 (Fig. 2B) or G2/M (Fig. 2C) phase was observed in time- and concentrationdependent manners. 


\subsection{LCY-2-CHO induced DNA fragmentation but not $\mathrm{LDH}$ release}

Degradation of DNA into a specific fragmentation pattern is a characteristic feature of apoptosis. In contrast to the random fragmentation with necrosis, apoptosis-associated DNA fragmentation is characterized by cleavage of the DNA at regular intervals, visualized on agarose gel electrophoresis as a DNA ladder consisting of multimers of approximately 200 base pairs. THP- 1 cells were incubated with vehicle (Fig. 3A, lane 1), 10 or $30 \mu \mathrm{M}$ LCY-2-CHO (Fig. 3A, lanes 2 and 3 ) alone for $24 \mathrm{~h}$, and the genomic DNA from these samples were subjected to agarose gel electrophoresis. A clear DNA fragmentation was observed in the LCY-2-CHO-treated group, and this pattern was less apparent in cells in the combination of zVAD-fmk $(100 \mu \mathrm{M})$ and LCY-2-CHO $(10$ or $30 \mu \mathrm{M})$ (Fig. 3A, lanes 5 and 6 ). In addition, no fragmentation pattern was seen in un-stimulated control group or only zVAD-fmk-treated cells (Fig. 3A, lanes 1 and 4). To confirm that LCY-2$\mathrm{CHO}$ indeed induced cell death through apoptotic pathway, we also used LDH release assay to assess the plasma membrane integrity. LDH is a stable cytosolic enzyme that is readily released in the early stage of necrosis, and only in the late stage of apoptosis [27]. As shown in Fig. 3B, little release of LDH (9\%) was detected in cells without stimulation, and cells treated with 10 or $30 \mu \mathrm{M}$ LCY-2-CHO alone for $24 \mathrm{~h}$ had a minimal effect on LDH release. These results may thus exclude the possibility that LCY-2-CHO activates a necrosis pathway in THP-1 cells. It is therefore suggested that the form of LCY-2-CHOelicited cell death is apoptosis.

\subsection{LCY-2-CHO-mediated cell apoptosis is caspase dependent}

Caspases have been shown to be key mediators of cell death in biological and biochemical analyses. With no exception, caspase-3 was an executioner for the death program in THP-1 cells in response to various noxious insults $[28,29]$. To explore whether LCY-2-CHO-mediated cell death is dependent on caspase activation, we next examined the effects of various caspase inhibitors on LCY2-CHO-induced cell death in THP-1 cells. These include zYVAD-fmk (caspases-1 and -4 inhibitor), zVDVAD-fmk (caspase-2 inhibitor), zVAD-fmk (non-selective caspase inhibitor), zVEID-fmk (caspase-6 inhibitor) and zIETDfmk (caspase-8 inhibitor). Although the study of Thornberry et al. [30] showed zVEID-fmk should inhibit other enzymes with the specificity (IVL)EXD (i.e. caspases- $6,-8$ and -10), the preference of this inhibitor is capsase-6 [31]. Results from Fig. 4A indicated that the apoptotic effect of LCY-2-CHO was not significantly affected by zYVADfmk and zVDVAD-fmk. In contrast, treatment of cells with zVAD-fmk $(30 \mu \mathrm{M})$, zVEID-fmk $(30 \mu \mathrm{M})$ or zIETD-fmk $(30 \mu \mathrm{M})$ significantly reduced the percentage of LCY-2CHO-mediated apoptotic cells by approximately $20 \%$ from $55 \pm 3 \%$ of LCY-2-CHO-treated group to $33 \pm 4 \%$ of zVAD-fmk-treated group, $36 \pm 3 \%$ of zVEID-fmk-treated group and $37 \pm 2 \%$ of zIETD-fmk-treated group. Moreover, zVAD-fmk at high concentration $(100 \mu \mathrm{M})$ almost completely blocked the apoptotic effect of LCY2 -CHO (55 $\pm 4 \%$ versus $7 \pm 2 \%$ of apoptotic cells). These suggest that caspases- $3,-6$ and -8 may play a major role in LCY-2-CHO stimulated cell death.

During apoptosis, several mediators such as caspases-3 and -6 deliberate disassembly of the cell into apoptotic bodies [32]. These downstream caspases are activated through proteolytic cleavage by upstream initiator caspases such as caspase- 8 . To verify LCY-2-CHO proapoptotic action is related to caspases activation, we determined the activity of caspase-3, which is central of several apoptotic pathways. Thus, procaspase-3 degradation, which is known an essential step for triggering caspase-3 activation and functioning, was examined. As shown in Fig. 4B, cells display significantly reduction of
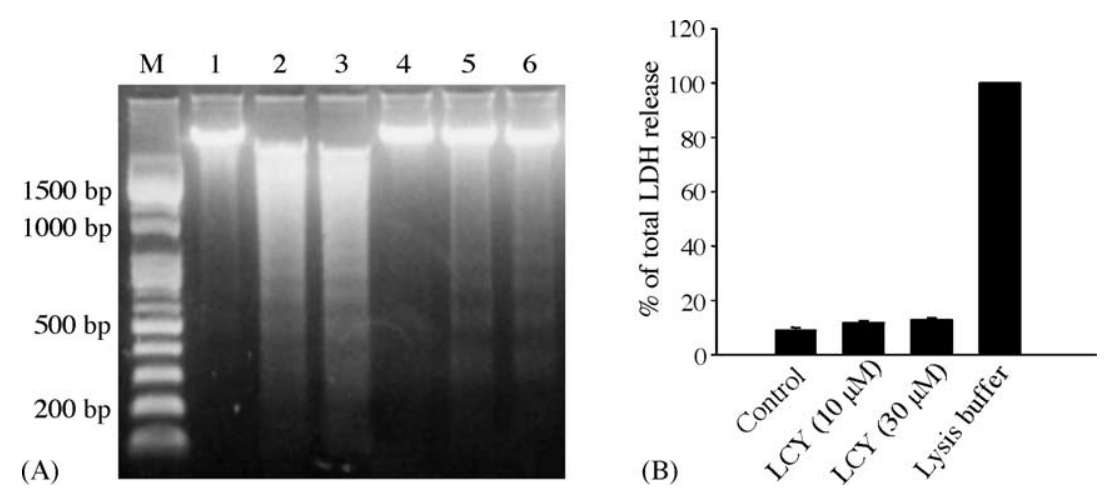

Fig. 3. Analysis of fragmented DNA and LDH release in THP-1 cells treated with LCY-2-CHO. (A) Cells were pretreated with vehicle or zVAD-fmk (100 $\mu$ M) for $30 \mathrm{~min}$ before addition with vehicle, or LCY-2-CHO $(10$ or $30 \mu \mathrm{M})$ for $24 \mathrm{~h}$. Genomic DNA was then isolated after treatment. DNA fragmentation was evaluated by electrophoresis on an agarose gel containing ethidium bromide and photographed under UV light. Lane M: DNA ladder marker; lane 1: untreated control; lane 2: treated with $10 \mu \mathrm{M} \mathrm{LCY-2-CHO;} \mathrm{lane} \mathrm{3:} \mathrm{treated} \mathrm{with} 30 \mu \mathrm{M} \mathrm{LCY-2-CHO;} \mathrm{lane} \mathrm{4:} \mathrm{treated} \mathrm{with} 100 \mu \mathrm{M}$ zVAD-fmk alone; lane 5: treated with $100 \mu \mathrm{M}$ zVAD-fmk and $10 \mu \mathrm{M}$ LCY-2-CHO; lane 6: treated with $100 \mu \mathrm{M}$ zVAD-fmk and $30 \mu \mathrm{M}$ LCY-2-CHO. Similar results were obtained in three independent experiments. (B) Cells were treated with 10 or $30 \mu \mathrm{M}$ LCY-2-CHO, or cell lysis buffer. LDH assay was then analyzed as described in Section 2. 

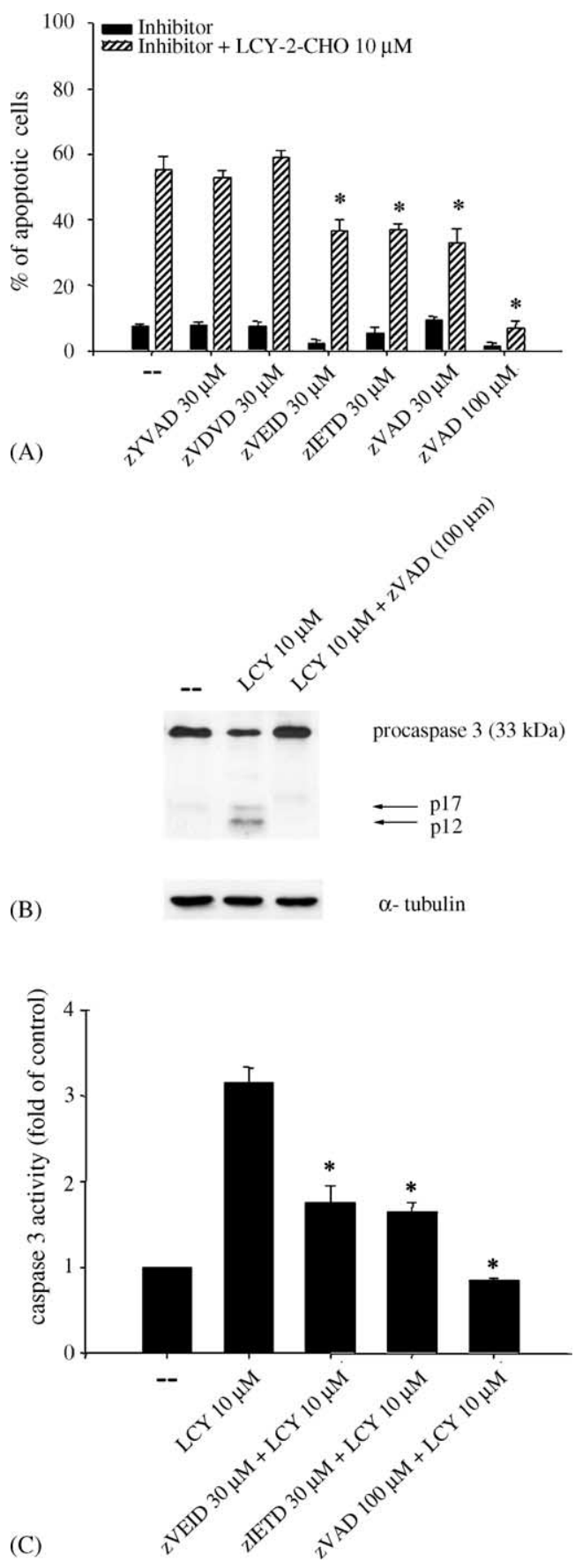

Fig. 4. Caspase-dependent apoptosis induced by LCY-2-CHO in THP-1 cells. (A) Cells were pretreated with vehicle, zYVAD-fmk $(30 \mu \mathrm{M})$, zVDVAD-fmk $(30 \mu \mathrm{M})$, zVEID-fmk $(30 \mu \mathrm{M})$, zIETD-fmk $(30 \mu \mathrm{M})$ or zVAD-fmk $(30$ and $100 \mu \mathrm{M})$ before addition with vehicle or LCY-2$\mathrm{CHO}(10 \mu \mathrm{M})$ for incubation of an additional $24 \mathrm{~h}$. Apoptotic cells were analyzed by flow cytometry using propidium iodide labeling. Data are presented as the mean \pm S.E.M. of five experiments. ${ }^{*} P<0.05$ as compared with the LCY-2-CHO-treated group. (B) Cells were pretreated with vehicle or zVAD-fmk $(100 \mu \mathrm{M})$ for $30 \mathrm{~min}$. Cells were then treated with LCY-2$\mathrm{CHO}(10 \mu \mathrm{M})$ and immunoblots of procaspase- 3 and active fragments (p17, p12) were determined after 24-h incubation of LCY-2-CHO. (C) Cells were pretreated with vehicle or zVAD-fmk $(100 \mu \mathrm{M})$, zVEID-fmk $(30 \mu \mathrm{M})$ or zIETD-fmk $(30 \mu \mathrm{M})$ for $30 \mathrm{~min}$. After $24 \mathrm{~h}$ treatment of LCY-2-CHO $(10 \mu \mathrm{M})$, cells were harvested and the activity of caspase- 3 was determined as described in Section 2. Data are presented as the mean \pm S.E.M. of five experiments. ${ }^{*} P<0.05$ as compared with the LCY-2-CHO-treated group. procaspase-3 within 24-h incubation in the presence of LCY-2-CHO. In cells treated with zVAD-fmk, the decrease of procaspase-3 was diminished. In parallel experiment, we also elucidated the activity of caspase3 by colorimetric assay using AcDEVD-pNA as the substrate for caspase-3. Similarly, LCY-2-CHO $(10 \mu \mathrm{M})$ obviously elevated caspase-3 activity and zVAD-fmk was capable of abrogating the stimulating effect of LCY-2-CHO. Moreover, the increase of caspase3 activity was also significantly attenuated in the presence of either zVEID-fmk $(30 \mu \mathrm{M})$ or zIETD-fmk $(30 \mu \mathrm{M})$ (Fig. 4C). These data indicated caspases-6 and -8 might be the upstream molecules of caspase- 3 involved in LCY-2-CHO-induced cell death.

\subsection{Reactive oxygen species (ROS), and cathepsin were not required for $\mathrm{LCY}$-2-CHO-induced cell death}

Recently both lysosomal damage and oxidative stress have been implicated in some models of cell death $[16,33,34]$. For example, cathepsin B is responsible for oxidative stress-induced cell death in neuronal cells [16]. To address whether ROS or cathepsin was relevant to the proapoptotic action of LCY-2-CHO, the effects of glutathione (GSH, $10 \mathrm{mM}$ ), $N$-acetyl cysteine (NAC, $10 \mathrm{mM}$ ), catalase $(500 \mathrm{U} / \mathrm{ml})$ and carboxyfullerene C60 $(50 \mu \mathrm{M})$, a free radical scavenger as powerful as an antioxidant agonist [21], MnTBAP $(100 \mu \mathrm{M})$, a cell-permeable superoxide dismutase mimetic $[35,36]$, pepstatin A $(3 \mu \mathrm{M})$ and CA074Me (cathepsin B inhibitor, $5 \mu \mathrm{M}$ ) were examined. The results indicated that all these antioxidants and cathepsin inhibitors we used were not able to reverse the cell death caused by LCY-2-CHO (Fig. 5A). In order to further verify whether ROS is involved in LCY-2-CHOinduced apoptosis, we also used the fluorescent dye DCFHDA to measure the intracellular ROS and $\mathrm{H}_{2} \mathrm{O}_{2}$ was added as a positive control. Similar results with the inhibitors, we did not detect the ROS production after LCY-2-CHO treatment (Fig. 5B).

\subsection{LCY-2-CHO-induced Bid cleavage, reduced mitochondrial membrane potential and the release of cytochrome $c$}

Previous studies showed that caspase- 8 cleaves Bid to form tBid, which, through direct association with antiapoptotic members of the Bcl-2 family, releases proapoptotic Bax or Bak to generate pores in the mitochondrial membrane, leading to cytochrome $c$ dependent-activated capase-3 pathway $[9,37]$. Since LCY-2-CHO is suggested to induce the activation of caspases- $3,-6$ and -8 by viewing the specific inhibitors in suppression of LCY-2-CHOinduced cell apoptosis, we sought to connect the caspase pathway to the mitochondrial apoptotic events, if they indeed exist in the case of LCY-2-CHO action. For this purpose, we first examined the Bid cleavage during LCY-2- 

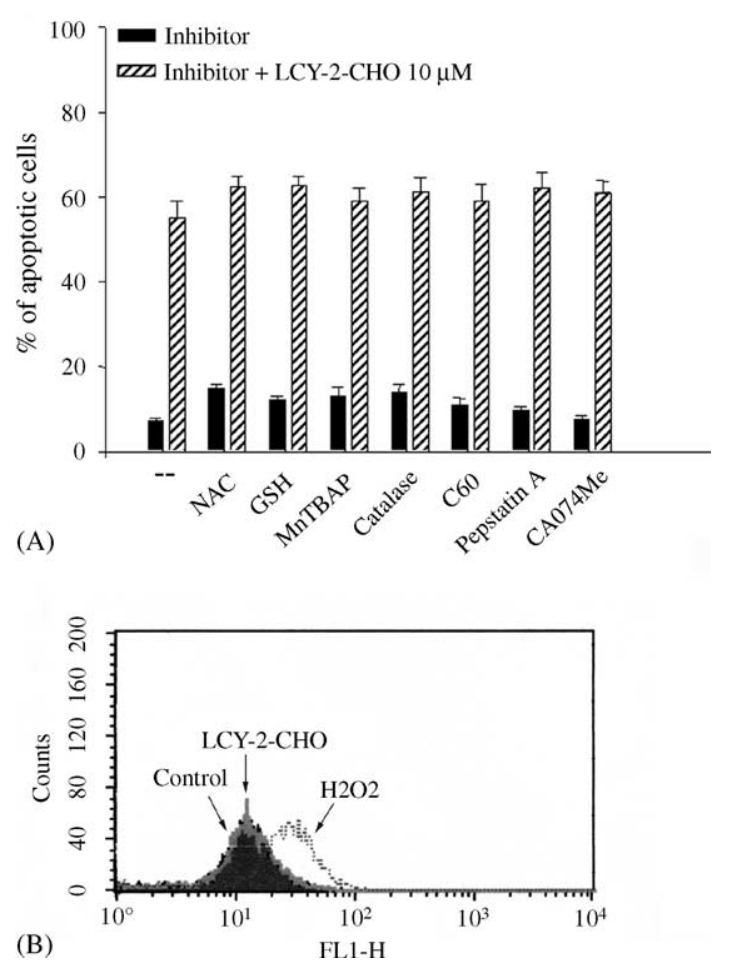

Fig. 5. ROS- and cathepsin-independent action of LCY-2-CHO in THP-1 cells. Cells were $30 \mathrm{~min}$ pretreated with $10 \mathrm{mM} \mathrm{NAC}, 10 \mathrm{mM} \mathrm{GSH}, 50 \mu \mathrm{M}$ carboxyfullerene (C60), $500 \mathrm{U} / \mathrm{ml}$ catalase, $100 \mu \mathrm{M}$ MnTBAP, $3 \mu \mathrm{M}$ pepstatin A or $5 \mu \mathrm{M}$ CA074Me before the treatment of LCY-2-CHO $(10 \mu \mathrm{M})$ for $24 \mathrm{~h}$. Cell viability was determined by flow cytometry using propidium iodide labeling. Data are presented as the mean \pm S.E.M. of four to five experiments.

CHO-induced apoptosis. LCY-2-CHO $(10 \mu \mathrm{M})$ decreased the level of Bid in a time-dependent manner, significantly at 6 and $9 \mathrm{~h}$ (Fig. 6A). After 9-h incubation with $10 \mu \mathrm{M}$ LCY-2-CHO in the presence of zVAD-fmk $(30 \mu \mathrm{M})$ or zIETD-fmk $(30 \mu \mathrm{M})$, LCY-2-CHO-induced Bid cleavage in THP-1 cells was effectively prevented (Fig. 6A). Second, the mitochondrial membrane potential was determined with the membrane potential sensitive dye CMXRos. Treatment with LCY-2-CHO $(10 \mu \mathrm{M})$ induced the loss of mitochondrial membrane potential compared to the control at $9 \mathrm{~h}$ time point. In the combination of zVADfmk $(30 \mu \mathrm{M})$ or zIETD-fmk $(30 \mu \mathrm{M})$ with LCY-2-CHO $(10 \mu \mathrm{M})$, the collapse of mitochondrial membrane potential was obviously prevented as compared to LCY-2-CHO treated alone (Fig. 6B), but the presence of caspase- 6 inhibitor zVEID-fmk failed to mimic such action (data not shown). Third, since increase in the permeability of the outer mitochondrial membrane leads to the release of several apoptotic factors, such as cytochrome $c$, we next investigated whether LCY-2-CHO-induced apoptosis in THP-1 cells involved the release of cytochrome $c$. The levels of extra-mitochondrial cytochrome $c$ were determined using an immunoblot analysis with anti-cytochrome $c$ antibody. The release of cytochrome $c$ readily increased upon LCY-2-CHO treatment and correlated with a decrease of mitochondrial membrane potential (Fig. 6C).

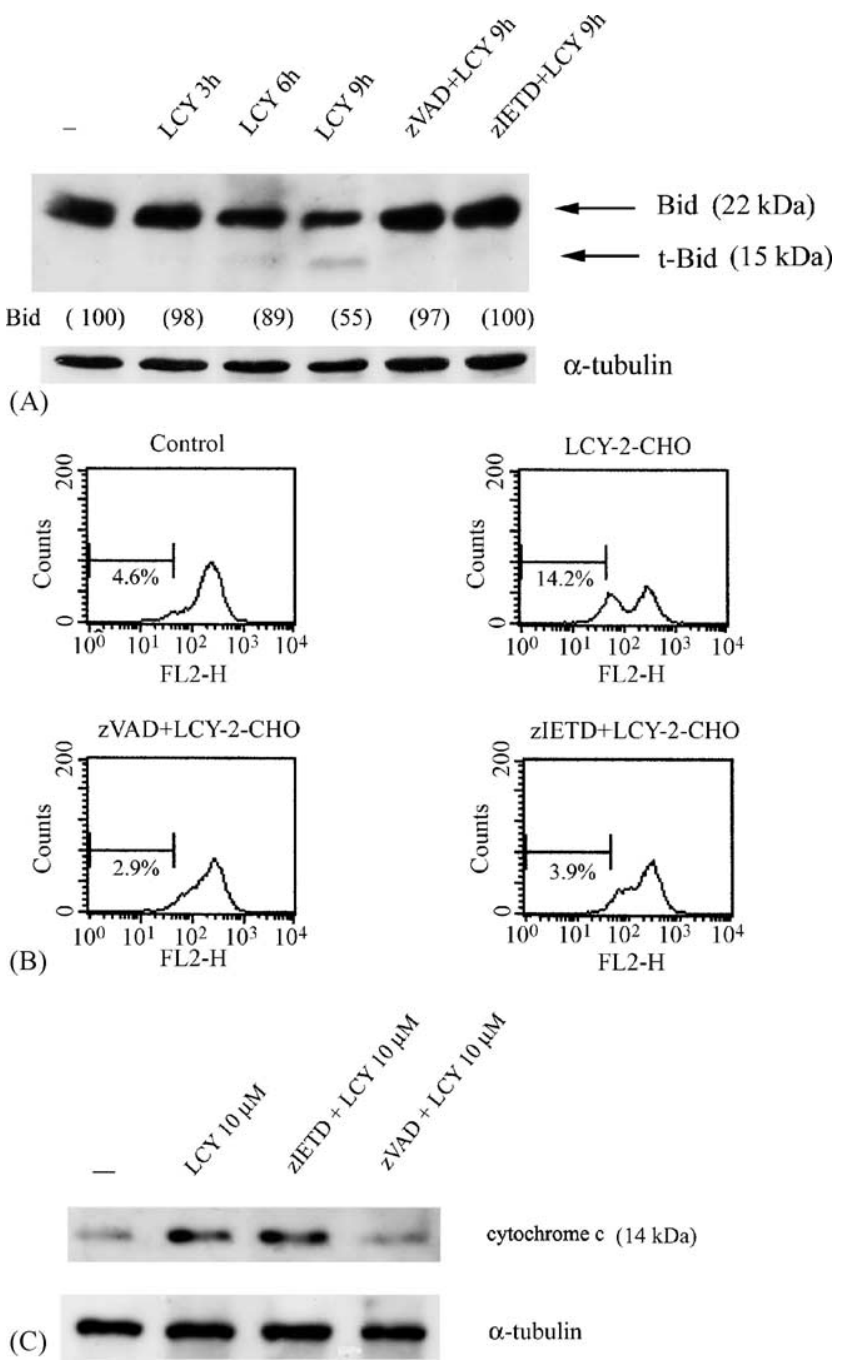

Fig. 6. LCY-2-CHO-elicited THP-1 cell apoptosis is associated with Bid cleavage, the loss of mitochondrial membrane potential and cytochrome $c$ release. (A) Immunoblot showed Bid cleavage after treatment of LCY-2$\mathrm{CHO}(10 \mu \mathrm{M})$ for the time indicated or in the presence of vehicle, zVADfmk $(30 \mu \mathrm{M})$ or zIETD-fmk $(30 \mu \mathrm{M})$ for $9 \mathrm{~h}$. (B) After THP-1 cells were cultured for $9 \mathrm{~h}$ in medium containing $10 \mu \mathrm{M} \mathrm{LCY}-2-\mathrm{CHO}$ in the presence of vehicle, zVAD-fmk $(30 \mu \mathrm{M})$ or zIETD-fmk $(30 \mu \mathrm{M})$, mitochondrial membrane potential was assessed by CMXRos staining. The percentages of cells losing $\Delta \psi_{\mathrm{m}}$ relative to the total were calculated and shown on the figure. Similar results were obtained in three independent experiments. (C) Cytochrome $c(14 \mathrm{kDa})$ was released into the cytosol of LCY-2-CHOtreated THP-1 cells. Cells were pretreated with vehicle, zVAD-fmk $(30 \mu \mathrm{M})$ or zIETD-fmk $(30 \mu \mathrm{M})$ for $30 \mathrm{~min}$. LCY-2-CHO was then added into the cells and incubated for $24 \mathrm{~h}$. After treatment, the cytosolic fraction of cells was immunoblotted with monoclonal antibody against cytochrome $c$. Data are representative of three independent experiments.

To show that cytochrome $c$ release is related to the activation of caspases, we pretreated THP-1 cells with a general caspase inhibitor, zVAD-fmk and caspase- 8 inhibitor, zIETD-fmk, prior to the addition of LCY-2-CHO. As shown in Fig. 6C, pretreatment of THP-1 cells with the zVAD-fmk reduced cytochrome $c$ release induced by LCY2-CHO. However, pretreatment of zIETD-fmk did not reduce the cytochrome $c$ release. These findings suggest that LCY-2-CHO-induced Bid cleavage through caspase-8 
activity leads to the loss of mitochondrial membrane potential, while LCY-2-CHO induced the release of cytochrome $c$ might result from other apoptotic pathway independent of caspase-8.

\subsection{Preference of LCY-2-CHO-induced apoptosis in malignant hematopoietic cells}

Extending to understand whether the apoptosis induced by LCY-2-CHO is cell-type specific or not, we also selected several cancer cell lines as compared to THP-1. Within 24-h incubation, Table 1 revealed that even though the apoptotic extents of CEM and HL-60 cells were less as compared to THP-1 cells, both leukemia cells were more susceptible to LCY-2-CHO-induced apoptosis than the other three adherent cell types examined. Concentration of $1 \mu \mathrm{M}$ was sufficient to achieve cell apoptosis in CEM cells, $10 \mu \mathrm{M}$ was required for HL-60, while the viability of three adherent cancer cells, PC3, HT29 and MCF-7, were unaffected in the presence of LCY-2-CHO at concentration as high as $30 \mu \mathrm{M}$. When concentration was increased to $30 \mu \mathrm{M}$ and incubation was extended to 3 days, the cell viability of PC3, HT29 and MCF-7 were $88 \pm 5 \%$, $65 \pm 1 \%$ and $100 \%$, respectively. Further treated cells with $100 \mu \mathrm{M}$ for 3 days, the cell viability of PC3, HT29 and MCF-7 were $36 \pm 1 \%, 36 \pm 1 \%$ and $80 \pm 5 \%$, respectively (data not shown). These results suggested that LCY2-CHO might be apoptotic for malignant hematopoietic cells, but not anchorage-dependent tumor cells.

\section{Discussion}

Apoptosis is under strict genetic control and a distinct morphology is detectable. In contrast, necrosis is a random process and results in cell lysis. During classical apoptosis, caspase proteins are recruited for activation of the apoptotic pathway $[12,13]$. Another hallmark of classical apoptosis is the fragmentation of DNA by an endogenous endonuclease, which cleaves double-stranded DNA between nucleosomes to produce mono- and oligonucleosomes. There is also a tight relationship between cell cycle and apoptotic responses. Cell cycle components such as $\mathrm{p} 53, \mathrm{pRb}$ and $\mathrm{E} 2 \mathrm{~F}$, have been shown to participate in both cell cycle progression and apoptosis. Apoptotic stimuli affect both cell proliferation and death through these regulators [4]. Most cancers require two or more mutations to deregulate the cell cycle and to overcome the apoptotic safeguards against inappropriate division. This study investigating the effect of a synthetic carbazole compound indicates that LCY-2-CHO could selectively induce cell death of human leukemia cells in concentration and time dependency within $1-30 \mu \mathrm{M}$. The results from the flow cytometric detection of propidium iodide stained cells and caspase- 3 activity assays indicated that cells treated with LCY-2-CHO were undergoing apoptosis. Cell death was also assayed by studying the integrity of plasma membrane, in order to determine whether necrosis was the form of cell death. LDH release assay excluded this possibility, as cells treated with LCY-2-CHO were negligible in this assay.

Two pathways of caspase activation during apoptosis have been described. The first one is mediated by death receptors, such as Fas, and controlled by caspase-8, which in turn activate downstream effector caspases. In the second pathway, diverse apoptotic signals converge at the mitochondrial level, inducing the release of cytochrome $c$ from the mitochondria into the cytosol. These two apoptotic pathways could be interconnected by the caspase-8-mediated cleavage of Bid, which triggers the activation of the mitochondrial pathway $[9,37]$. Once in the cytosol, cytochrome $c$ binds to its cytosolic partner apoptotic protease activating factor-1 (Apaf-1), the human homologue of Caenorhabditis elegans apoptotic protein CED-4, and induces the oligomerization of Apaf-1/cytochrome $c$ complex in a dATP/ATP-dependent manner [38]. This multimeric complex, named "apoptosome", is sufficient to recruit the initiator caspase, procaspase- 9 , to the complex and induces procaspase- 9 autoactivation. The activated caspase- 9 is released from the apoptosome and subsequently initiates a caspase cascade involving the effector caspases such as caspases-3, -6, and -7 [39]. Using broad-spectrum caspase inhibitor, zVAD-fmk, we found that zVAD-fmk significantly protect cells from LCY-2CHO-induced apoptosis. Similar results were also obtained from caspase-6 preference inhibitor (zVEID-fmk) and caspase- 8 preference inhibitor (zIETD-fmk) treatments prior to the addition of LCY-2-CHO in THP-1 cells.

Table 1

Cell specificity of apoptosis to LCY-2-CHO

\begin{tabular}{clcccc}
\hline$\mu \mathrm{M}$ & THP-1 & CEM & HL-60 & PC3 & HT29 \\
\hline 0 & $11.6 \pm 4.7$ & $5.8 \pm 0.6$ & $2.4 \pm 0.2$ & $3.1 \pm 0.4$ & $3.5 \pm 0.8$ \\
1 & $22.9 \pm 0.4^{*}$ & $10.5 \pm 1.8^{*}$ & $2.1 \pm 0.3$ & $4.5 \pm 0.1$ & $2.8 \pm 0.3$ \\
3 & $36.3 \pm 0.2^{*}$ & $10.9 \pm 1.3^{*}$ & $2.9 \pm 0.8$ & $5.1 \pm 0.4$ & $3.1 \pm 0.8$ \\
10 & $54.9 \pm 3^{*}$ & $17.9 \pm 2.1^{*}$ & $29.1 \pm 3.0^{*}$ & $3.9 \pm 0.7$ & $0.4 \pm 0.1$ \\
30 & $68.1 \pm 5.7^{*}$ & $25.2 \pm 3.1^{*}$ & $41.5 \pm 2.5^{*}$ & $4.7 \pm 1.0$ & $0.2 \pm 0.1$ \\
\hline
\end{tabular}

Flow cytometric analysis of sub-G1 phase accumulation in THP-1, CEM, HL-60. PC3, HT29, and MCF-7 cells. Cells were incubated with vehicle, indicated concentrations of LCY-2-CHO for $24 \mathrm{~h}$. Following incubation, cells were stained by propidium iodide and apoptotic cells were determined by flow cytometry. Each data represents the mean \pm S.E.M. of at least three independent experiments.

${ }^{*} P<0.05$ as compared with the control group without LCY-2-CHO treatment. 
Moreover, LCY-2-CHO-elicited caspase-3 activation might result from upstream caspases, such as caspases- 8 and -6 , since zVEID-fmk and zIETD-fmk also blocked the activation of caspase- 3 . These results suggest that activation of caspase cascade is contributed to the apoptotic effect of LCY-2-CHO, and caspase-8 might play an initiating role.

The Bid cleavage to tBid could induce the loss of membrane potential, then leading to the cytochrome $c$ release into cytosol [40,41]. Our current data provide evidence that the apoptotic events upstream effector caspase activation by LCY-2-CHO involve caspase-8. Although caspase-8 inhibitor could prevent the mitochondrial membrane potential loss, the release of cytochrome $c$ into the cytosol could not be inhibited. There have been data proved to explain the mitochondrial membrane potential loss-independent cytochrome $c$ release. BH3-only proteins of Bcl-2 family, such as Bik, could induce cytochrome $c$ release but without mitochondrial membrane potential loss [42]. In addition, an in vitro model system shows the release of cytochrome $c$ may occur via modulation of mitochondrial volume by hypotonic shock or potassium selective ionophore. Under these circumstances, the mitochondria remain intact and functionally active [43]. Thus, different proapoptotic Bcl-2 members or other molecules might be involved in apoptosis of either reduction or maintenance of mitochondrial membrane potential. In LCY-2-CHO-treated THP-1 cells, even though caspase6 inhibitor zVEID-fmk could inhibit the caspase-3 activation and cell apoptosis, it did not alter mitochondrial membrane potential loss. Thus, LCY-2-CHO-mediated apoptosis pathway is suggested to involve caspase$8 \rightarrow$ Bid cleavage $\rightarrow$ loss of mitochondrial membrane potential $\rightarrow$ cytochrome $c$ release $\rightarrow$ effector caspase- 3 activation, and caspase- $8 \rightarrow$ caspase- $6 \rightarrow$ caspase- 3 activation. Moreover, another mitochondrial membrane potential loss-independent pathway might promote cytochrome $c$ release and caspase activation (Fig. 7).

Although increase of ROS in THP-1 cell apoptosis in response to various stimuli was shown previously [44,45], our study indicated that LCY-2-CHO-elicited cell apoptosis was unaffected by GSH, NAC, MnTBAP, catalase and carboxyfullerene. Thus, it appears that ROS cannot be attributed to the apoptotic action of LCY-2-CHO in THP-1 cells. In addition, since inhibitor of cathepsin B suppressed oxysterol-stimulated THP-1 apoptosis was reported [46], we also determined whether cathepsin B and LCY-2-CHO-mediated cell death might be causally associated. Using a cathepsin inhibitor CA074Me, we found that cathepsin might not play a role in LCY-2CHO-mediated cell apoptosis. Therefore, it appears that LCY-2-CHO-induced apoptosis of THP-1 leukemia cells was independent of either ROS production or cathepsin activation.

In addition to THP-1, LCY-2-CHO was also tested of cytotoxicity against several human cancer cell lines. As

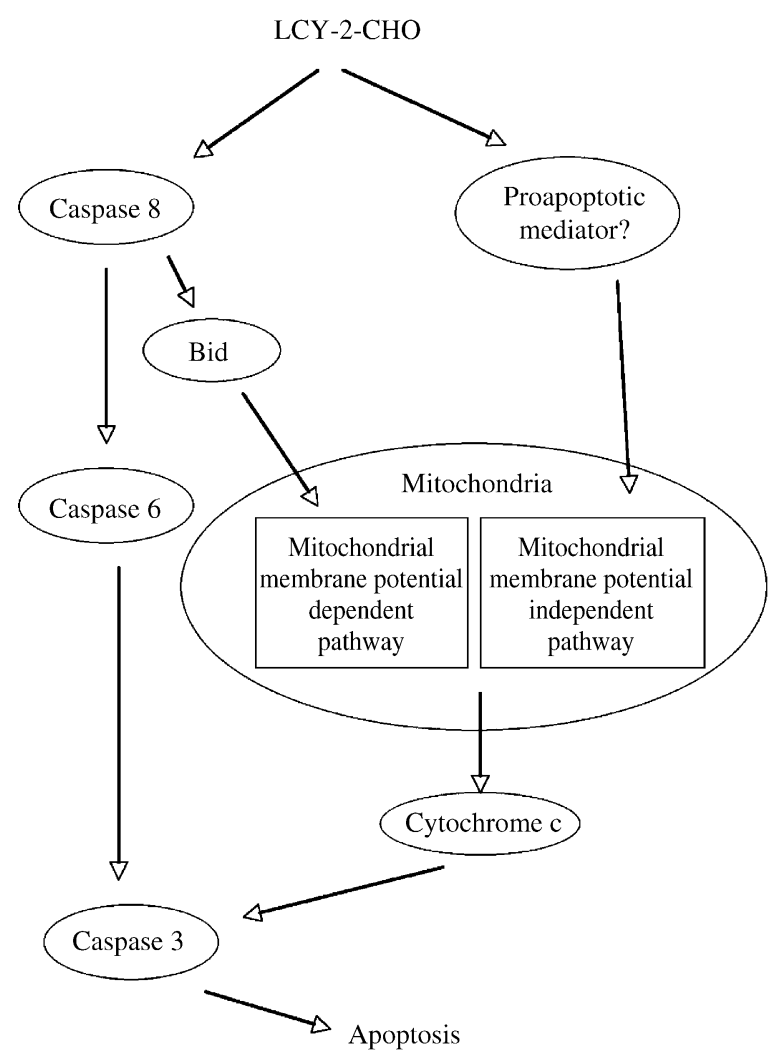

Fig. 7. Schematic summary of apoptotic pathways of LCY-2-CHO in THP1 cells.

a result, LCY-2-CHO was apparently cytotoxic against the leukemia lines (CEM and HL-60), but had little effect on the cell viability of PC3 (prostate cancer), HT29 (colon cancer) and MCF-7 (breast cancer) cells. These results suggest that LCY-2-CHO might be selectively cytotoxic against certain leukemia cells. This action would raise great interests to elucidate the distinct apoptotic regulation between cancer cell types in the future. Whether cell adhesion-mediated drug resistance and/or discrepancy of apoptotic gene mutations, as proposed previously $[47,48]$, may contribute to the less sensitivity of LCY-2-CHO in adherent cells needs to be elucidated.

In conclusion, these results showed that LCY-2-CHO, a synthetic anti-inflammatory compound, preferentially induced cell death in leukemia cells. This action occurs primarily through the apoptotic pathways, which include caspase- 8 activation, Bid cleavage, mitochondrial changes, and caspases- 6 and -3 activation. This work therefore represents a potentially new area in accelerating the development of specific anti-leukemia agents. Moreover, the action in the resolution of inflammatory responses by LCY2-CHO would ameliorate tissue damage that occurs either during cancer development or after therapeutic treatment with some anti-tumor drugs. The dual actions of LCY-2$\mathrm{CHO}$ thus provide a new approach for chemotherapeutic drug development. 


\section{Acknowledgements}

This work was supported by the National Science Council of Taiwan (NSC93-2314-B075-023) and TaoYuan General Hospital Department of Health the Execute Yuan, Taiwan (PTH9403).

\section{References}

[1] Meagher LC, Savill JS, Baker A, Fuller RW, Haslett C. Phagocytosis of apoptotic neutrophils does not induce macrophage release of thromboxane $B_{2}$. J Leukoc Biol 1992;52:269-73.

[2] Haslett C. Granulocyte apoptosis, and inflammatory disease. Br Med Bull 1997;53:669-83.

[3] Taylor EL, Megson IL, Haslett C, Rossi AG. Nitric oxide: a key regulator of myeloid inflammatory cell apoptosis. Cell Death Differ 2003;10:418-30.

[4] King KL, Cidlowski JA. Cell cycle regulation and apoptosis. Annu Rev Physiol 1998;60:601-17.

[5] Djavaheri-Mergny M, Wietzerbin J, Besancon F. 2-Methoxyestradiol induces apoptosis in Ewing sarcoma cells through mitochondrial hydrogen peroxide production. Oncogene 2003;22:2558-67.

[6] Hostanska K, Vuong V, Rocha S, Soengas MS, Glanzmann C, Saller R, et al. Recombinant mistletoe lectin induces $\mathrm{p} 53$-independent apoptosis in tumor cells and cooperates with ionizing radiation. $\mathrm{Br} \mathrm{J}$ Cancer 2003;88:1785-92.

[7] Utz PJ, Anderson P. Life and death decisions: regulation of apoptosis by proteolysis of signaling molecules. Cell Death Differ 2000;7:589602.

[8] Ward C, Dransfield I, Chilvers ER, Haslett C, Rossi AG. Pharmacological manipulation of granulocyte apoptosis: potential therapeutic targets. Trends Pharmacol Sci 1999;20:503-59.

[9] Newmeyer DD, Ferguson-Miller S. Mitochondria: releasing power for life and unleashing the machineries of death. Cell 2003;112:481-90.

[10] Tsujimoto Y. Cell death regulation by the Bcl-2 protein family in the mitochondria. J Cell Physiol 2003;195:158-67.

[11] Enari M, Sakahira H, Yokoyama H, Okawa K, Iwamatsu A, Nagata S, et al. A caspase-activated DNase that degrades DNA during apoptosis, and its inhibitor ICAD. Nature 1998;391:43-50.

[12] Ha KS, Kim KM, Kwon YG, Bai SK, Nam WD, Yoo YM, et al. Nitric oxide prevents 6-hydroxydopamine-induced apoptosis in PC12 cells through cGMP-dependent PI3 kinase/Akt activation. FASEB J 2003;17:1036-47.

[13] Tibbetts MD, Zheng L, Lenardo MJ. The death effector domain protein family: regulators of cellular homeostasis. Nat Immunol 2003;4:404-9.

[14] Stefanis L, Troy CM, Qi H, Greene LA. Inhibitors of trypsin-like serine proteases inhibit processing of the caspase Nedd-2 and protect PC-12 cells and sympathetic neurons from death evoked by withdrawal of trophic support. J Neurochem 1997;69:1425-37.

[15] Wu LW, Reid S, Ritchie A, Broxmeyer HE, Donner DB. The proteasome regulates caspase-dependent and caspase-independent protease cascades during apoptosis of MO7e hematopoietic progenitor cells. Blood Cells Mol Dis 1999;25:20-9.

[16] Gray J, Haran MM, Schneider K, Vesce S, Ray AM, Owen D, et al. Evidence that inhibition of cathepsin-B contributes to the neuroprotective properties of caspase inhibitor Tyr-Val-Ala-Asp-chloromethyl ketone. J Biol Chem 2001;276:32750-5.

[17] Lee CY, Kuo SC, Teng CM, Huang LJ. Synthesis antiplatelet activity of 9-benzyl-3-hydroxymethylcarbazoles. Chin Pharm J 2002;32:2534.

[18] Lee CY, Huang LJ, Wang JP, Kuo SC. Anti-inflammatory activity of 9substituted benzyl-3-substituted carbazole derivatives. Chin Pharm J 2002;54:35-40.
[19] Tsao LT, Lee CY, Huang LJ, Kuo SC, Wang JP. Inhibition of lipopolysaccharide-stimulated nitric oxide production in RAW 264.7 macrophages by a synthetic carbazole, LCY-2-CHO. Biochem Pharmacol 2002;63:1961-8.

[20] Ho FM, Lai CC, Huang LJ, Kuo TS, Chao CM, Lin WW, et al. LCY-2$\mathrm{CHO}$ inhibits lipopolysaccharide-induced inflammatory mediator expression through inhibition of the p38 mitogen-activated protein kinase signaling pathway. Br J Pharmacol 2004;141:1037-47.

[21] Sherwood SW, Schimke RT. Cell cycle analysis of apoptosis using flow cytometry. Methods Cell Biol 1995;46:77-9.

[22] Wang IC, Tai LA, Lee DD, Kanakamma PP, Shen CK, Luh TY, et al. $\mathrm{C}(60)$ and water-soluble fullerene derivatives as antioxidants against radical-initiated lipid peroxidation. J Med Chem 1999;42:4614-20.

[23] Hsu MJ, Cheng JS, Huang HC. Effect of saikosaponin, a triterpene saponin, on apoptosis in lymphocytes: association with c-myc, p53, and bcl-2 mRNA. Br J Pharmacol 2000;131:1285-93.

[24] Mathony M, Hong Y, Kemp BK, Barrientos AA, Erusalimsky JD. Evaluation of fluorescent dyes for the detection of mitochondrial membrane potential changes in cultured cardiomyocytes. Cardiovasc Res 2000;46:126-38.

[25] Chen C, Lin H, Karanes C, Pettit GR, Chen BD. Human THP-1 monocytic leukemic cells induced to undergo monocytic differentiation by bryostatin 1 are refractory to proteasome inhibitor-induced apoptosis. Cancer Res 2000;60:4377-85.

[26] Huth W, Pauli C, Möller U. Immunochemical detection of CoAmodified mitochondrial matrix proteins. Biochem J 1996;320:451-7.

[27] Nargi-Aizenman JL, Griffin DE. Sindbis virus-induced neuronal death is both necrotic and apoptotic and is ameliorated by $N$-methyl-Daspartate receptor antagonists. J Virol 2001;75:7114-21.

[28] Vicca S, Hennequin C, Nguyen-khoa T, Massy ZA, Descamps-Latscha B, Drueke TB, et al. Caspase-dependent apoptosis in THP-1 cells exposed to oxidized low-density lipoproteins. Biochem Biophys Res Commun 2000;273:948-54.

[29] Wosikowski K, Mattern K, Schemainda I, Hasmann M, Rattel B, Loser R, et al. WK175 a novel antitumor agent, decreases the intracellular nicotinamide adenine dinucleotide concentration and induces the apoptotic cascade in human leukemia cells. Cancer Res 2002;62: 1057-62.

[30] Thornberry NA, Rano TA, Peterson EP, Rasper DM, Timkey T, Garcia-Calvo M, et al. A combinatorial approach defines specificities of members of the caspase family and granzyme B. Functional relationships established for key mediators of apoptosis. J Biol Chem 1997;272:17907-11.

[31] Gregoli PA, Bondurant MC. Function of caspases in regulating apoptosis caused by erythropoietin deprivation in erythroid progenitors. J Cell Physiol 1999;178:133-43.

[32] Rosen A, Casciola-Rosen L. Macromolecular substrates for the ICElike proteases during apoptosis. J Cell Biochem 1997;64:50-4.

[33] Fiers W, Beyaert R, Declercq W, Vandenabeele P. More than one way to die: apoptosis, necrosis and reactive oxygen damage. Oncogene 1999;18:7719-30.

[34] Yuan XM, Li W, Dalen H, Lotem J, Kama R, Sachs L, et al. Lysosomal destabilization in p53-induced apoptosis. Proc Natl Acad Sci USA 2002;99:6286-91.

[35] Szabo C, Day BJ, Salzman AL. Evaluation of the relative contribution of nitric oxide and peroxynitrite to the suppression of mitochondrial respiration in immunostimulated macrophages using a manganese mesoporphyrin superoxide dismutase mimetic and peroxynitrite scavenger. FEBS Lett 1996;381:82-6.

[36] Day BJ, Fridovich I, Crapo JD. Manganic prophyrins possess catalase activity and protect endothelial cells against hydrogen peroxide mediated injury. Arch Biochem Biophys 1997;347:256-62.

[37] Green DR, Reed JC. Mitochondria and apoptosis. Science 1998;281: 1309-12.

[38] Hu Y, Benedict MA, Ding L, Nunez G. Role of cytochrome $c$ and dATP/ATP hydrolysis in Apaf-1-mediated caspase-9 activation and apoptosis. EMBO J 1999; 18:3586-95. 
[39] Srinivasula SM, Ahmad M, Fernandes-Alnemri T, Alnemri ES. Autoactivation of procaspase- 9 by Apaf-1-mediated oligomerization. Mol Cell 1998;1:949-57.

[40] Reed JC. cytochrome $c$ : can't live with it—can't live without it. Cell 1997;91:559-62.

[41] Vander Heiden MG, Chandel NS, Williamson EK, Schumacker PT, Thompson CB. Bcl-xl regulates the membrane potential and volume homeostasis of mitochondria. Cell 1997;91:627-37.

[42] Shimizu S, Tsujimoto Y. Proapoptotic BH3-only Bcl-2 family members induce cytochrome $c$ release, but not mitochondrial membrane potential loss, and do not directly modulate voltage-dependent anion channel activity. Proc Natl Acad Sci USA 2000;97:577-82.

[43] Gogvadze V, Robertson JD, Enoksson M, Zhivotovsky B, Orrenius S. Mitochondrial cytochrome $c$ release may occur by volume-dependent mechanisms not involving permeability transition. Biochem $\mathrm{J}$ 2004;378:213-7.
[44] Sawada T, Hashimoto S, Furukawa H, Tohma S, Inoue T, Ito K, et al. Generation of reactive oxygen species is required for bucillamine, a novel anti-rheumatic drug, to induce apoptosis in concert with copper. Immunopharmacology 1997;35:195-202.

[45] Yoo YC, Watanabe R, Koike Y, Mitobe M, Shimazaki K, Watanabe S, et al. Apoptosis in human leukemic cells induced by lactoferricin, a bovine milk protein-derived peptide: involvement of reactive oxygen species. Biochem Biophys Res Commun 1997;237:624-8.

[46] Li W, Dalen H, Eaton JW, Yuan XM. Apoptotic death of inflammatory cells in human atherom. Arterioscler Thromb Vasc Biol 2001;21:1124-30.

[47] Lowe SW, Lin AW. Apoptosis in cancer. Carcinogenesis 2000;21:48595.

[48] Shain KH, Dalton WS. Cell adhesion is a key determinant in de novo multidrug resistance (MDR): new targets for the prevention of acquired MDR. Mol Cancer Ther 2001;1:69-78. 